\title{
Simulation of the Indian summer monsoon using comprehensive atmosphere-land interactions, in the absence of two-way air-sea interactions
}

\author{
Young-Kwon Lim ${ }^{1,4, *}$, D. W. Shin ${ }^{1}$, Steven Cocke ${ }^{1}$, Sung-Dae Kang ${ }^{2}$, Hae-Dong Kim ${ }^{3}$ \\ ${ }^{1}$ Center for Ocean-Atmospheric Prediction Studies (COAPS), Florida State University, Tallahassee, Florida 32306-2840, USA \\ ${ }^{2}$ National Typhoon Center, Korea Meteorological Administration, Jeju 699-942, Republic of Korea \\ ${ }^{3}$ Department of Environmental Conservation, Keimyung University, Daegu 704-701, Republic of Korea \\ ${ }^{4}$ Present address: NASA / Goddard Space Flight Center, Greenbelt, Maryland 20771, USA
}

\begin{abstract}
Community Land Model version 2 (CLM2) as a comprehensive land surface model and a simple land surface model (SLM) were coupled to an atmospheric climate model to investigate the role of land surface processes in the development and the persistence of the South Asian summer monsoon. Two-way air-sea interactions were not considered in order to identify the reproducibility of the monsoon evolution by the comprehensive land model, which includes more realistic vertical soil moisture structures, vegetation and 2-way atmosphere-land interactions at hourly intervals. In the monsoon development phase (May and June), comprehensive land-surface treatment improves the representation of atmospheric circulations and the resulting convergence/divergence through the improvements in differential heating patterns and surface energy fluxes. Coupling with CLM2 also improves the timing and spatial distribution of rainfall maxima, reducing the seasonal rainfall overestimation by $\sim 60 \%$ (1.8 $\mathrm{mm} \mathrm{d}^{-1}$ for SLM, $0.7 \mathrm{~mm} \mathrm{~d}^{-1}$ for CLM2). As for the interannual variation of the simulated rainfall, correlation coefficients of the Indian seasonal rainfall with observation increased from 0.21 (SLM) to 0.45 (CLM2). However, in the mature monsoon phase (July to September), coupling with the CLM2 does not exhibit a clear improvement. In contrast to the development phase, latent heat flux is underestimated and sensible heat flux and surface temperature over India are markedly overestimated. In addition, the moisture fluxes do not correlate well with lower-level atmospheric convergence, yielding correlation coefficients and root mean square errors worse than those produced by coupling with the SLM. A more realistic representation of the surface temperature and energy fluxes is needed to achieve an improved simulation for the mature monsoon period.
\end{abstract}

KEY WORDS: Indian summer monsoon $\cdot$ Monsoon precipitation $\cdot$ Climate modeling $\cdot$ Atmosphereland interaction $\cdot$ CLM2 $\cdot$ SLM

Resale or republication not permitted without written consent of the publisher

\section{INTRODUCTION}

The differential heating distribution between land and ocean is one of the key factors for large-scale monsoon development (Krishnamurti \& Ramanathan 1982, Zhang $\&$ Krishnamurti 1996). Accurate distribution of differential heating in a global climate model is, therefore, essential for producing a realistic monsoon development. The heating over land manifested by land surface processes is particularly important because it is closely connected with horizontal and vertical monsoon circulation and the surface hydrological cycle (Xue et al. 2006).
The present study investigated how much the improved land surface processes are able to produce substantial aspects of monsoon evolution for the entire monsoon period without including 2-way air-sea interactions. For this purpose, we couple a climate model with 2 different land surface models, one with a simple land surface representation and one with a comprehensive land surface representation. Previous model studies on land surface processes have emphasized the role of advanced land surface parameterizations in simulating Asian summer monsoon structures. Sud \& Smith (1985), Yasunari et al. (2006) and Kang \& Hong 
(2008) investigated the importance of surface albedo and roughness that is dependent on vegetation type. Meehl (1994) compared the relative contributions of surface albedo and soil moisture for simulation of the seasonal monsoon precipitation. The study clarified the strong positive feedback between soil moisture and precipitation. Yasunari (2007) suggested that surface moisture anomalies significantly affect the atmosphere under arid conditions. The study also identified that vegetation representation is very important for the formation of moist monsoonal flow toward the Asian continent. From the comparison of 2 different land surface parameterizations, Xue et al. (2004) concluded that comprehensive land surface parameterization with explicit vegetation representation is crucial for a realistic monsoon simulation for early monsoon development, whereas the simple parameterization without detailed vegetation information produces excessive precipitation. However, the study only considered the period of pre-monsoon to monsoon development phase for a particular year. Other land surface processes including soil moisture and evaporation were not intensively investigated for the entire monsoon period over multiple years. In addition, many other studies tend to focus more on the early monsoon development rather than considering entire monsoon evolution simulated under comprehensive atmosphere-land interactions (Saha et al. 2010). In contrast to these previous studies, the present study investigated the evolution of the Indian summer monsoon by focusing on the relative influence of comprehensive land surface processes to a simple land surface treatment, from pre-monsoon to the monsoon termination period. Surface temperature, surface pressure, thermodynamic fluxes and their relationship with atmospheric convergence and upperlevel divergence were investigated to identify the role of different land surface processes in the simulation of monsoon precipitation in different monsoon phases (development and mature phases).

\section{METHODS}

\subsection{Models}

The Florida State University/Center for OceanAtmospheric Prediction Studies (FSU/COAPS) climate model (Cocke \& LaRow 2000) is coupled to 2 different land surface models. One is a simple land surface model (SLM) and the other is the National Center for Atmospheric Research (NCAR) Community Land Model version 2 (CLM2) (Bonan et al. 2002). The SLM consists of a 3-layer soil temperature based on the force-restore method, whereas the CLM2 is a comprehensive model that includes detailed biogeophysical processes over the land surface. In the SLM, seasonally varying climatological values for soil moisture, albedo and roughness are prescribed based on US Geological Survey (USGS) data. Surface fluxes and corresponding surface temperature are obtained via similarity theory in consideration of surface energy balance.

The CLM2 consists of 10 layers for soil temperature and soil water with explicit treatment of liquid water and ice. The surface in each grid cell in the CLM2 is characterized by 5 land types: glacier, lake, wetland, urban and vegetated. A vegetated portion is further divided into patches of up to 4 out of 16 possible plant functional types, each with its own leaf and stem area index and canopy top and bottom height so that the local biophysical processes and the resulting surface flux of heat and moisture can be better resolved. Shin et al. (2005) showed that the SLM has cold biases in summer surface temperature forecasts over most of the land surface mainly because of excess latent heat and weak sensible heat fluxes, whereas the CLM2 is capable of reducing the summer cold bias of globally averaged surface air temperature (Zeng et al. 2002, Dai et al. 2003). Based on this difference between the SLM and CLM2, we will explore whether the comprehensive land surface information and processes in the CLM2 produce considerably more realistic monsoon structures and development compared with the SLM.

\subsection{Experimental design}

The CLM2 was coupled to the FSU/COAPS climate model $\left(\sim 1.8^{\circ}\right.$ longitude $\times$ latitude Resolution; T63) at $1 \mathrm{~h}$ intervals (CLM2-coupled). We used the NCAR Community Climate Model (CCM) radiation and boundary physics, and the model physics for the convective precipitation process is parameterized by the relaxed Arakawa-Schubert scheme developed at the Naval Research Laboratory (Rosmond 1992). To identify only the effect of comprehensive land surface processes, no air-sea interactions were considered; this was accomplished using weekly averaged prescribed Reynolds sea surface temperature (SST) (Reynolds et al. 2002). Hourly averaged atmospheric forcings provided by the atmospheric model (i.e. total incident solar radiation, precipitation, lowest model-level temperature, lowest horizontal winds, specific humidity, pressure and height above surface) were passed to the CLM2 so that the CLM2 could calculate and provide the atmospheric model with surface variables, including surface temperature, surface wind stress, radiative values (e.g. surface albedo and upward long wave radiation) and flux values (e.g. latent heat and sensible heat), at 1-h intervals. 
Atmospheric data for $10 \mathrm{yr}, 1994-2003$, were generated via seasonal integration from 1 March to 30 September each year. The atmospheric initial conditions, provided by the European Centre for Medium-Range Weather Forecasts 40 (ERA40) reanalysis, were available at T106 $\left(\sim 1.125^{\circ}\right.$ longitude $\times$ latitude resolution). Ocean information was obtained from weekly updated Reynolds SST, and land model initial conditions for the climate model were obtained from the 20 yr spinup climatological simulations. The initial data for these spinup simulations are the same as those used by Bonan et al. (2002). Monsoon developments produced from the above coupling strategy were compared with those produced by the climate model coupled with the SLM (SLM-coupled). Because of the limited availability of ERA40 reanalysis data, which ends in August 2002, we compared the climatological monsoon structure of modeled data with that of the ERA40 for $9 \mathrm{yr}$ (1994-2002). For precipitation, simulated fields were compared with Climate Prediction Center Merged Analysis of Precipitation (CMAP) data (Xie \& Arkin 1996).

\section{RESULTS}

\subsection{Distribution of surface heating, latent heat flux and sensible heat flux}

Geographical distributions of surface temperatures and latent/sensible heat fluxes averaged over May through September, the period of the early and mature Indian summer monsoon, are shown in Fig. 1 to demonstrate the improved simulation over land by the CLM2. It is evident that the SLM-coupled has cold biases over land, which is more obvious over India (Fig. 1,C,d). Most subtropical land areas, including India, exhibit lower temperatures than the SST over the Indian Ocean, indicating an adverse heating distribution for monsoon development (Meehl 1994, Li \& Yanai 1996). The CLM2-coupled, by contrast, substantially reduces these cold biases over land (Fig. 1b,d). Although some overestimation is found when the CLM2-coupled is compared with ERA40, the temperature fields demonstrate the ability of the CLM2coupled to produce a more reasonable differential heating distribution. Seasonal evolution also shows that observed variation with the highest temperature in May over India is successfully reproduced by the use of CLM2-coupled (long dashed line, Fig. 1d). By contrast, the SLM-coupled produces the gradual upward trend without the highest peak in May (short dashed line, Fig. 1d)

To identify the reason for the improvement of the surface temperature, sensible heat and latent heat flux fields for May-August are plotted. The SLM-coupled produces substantially larger latent heat flux and smaller sensible heat flux than the CLM2-coupled (Fig. 1e-g,i-k). This difference between SLM and CLM2 is more obvious over the land area (e.g. India and Southeast Asia). The CLM2-coupled exhibits reduced latent heat flux and increased sensible heat flux, which may be related to the reduced cold biases of the land surface temperature. It is evident from the comparison of the seasonal evolution with the reanalysis that the CLM2-coupled produces a more reasonable evolution of the latent heat flux over India (Fig. 1h), whereas the SLM-coupled generates the excessive latent heat flux for all months. Latent heat in the CLM2-coupled, however, reaches the maximum earlier (June and July) than observations (July and August) and is underestimated in the mature phase (Fig. 1h). This latent heat flux pattern may be a result of excessive land surface temperature (Fig. 1d) that may cause a little reduction in sensible heat flux (Fig. 11) and, ultimately, an underestimated latent heat flux. It implies that the CLM2-coupled may produce underestimated precipitation in the mature monsoon stage, which will be further discussed in Section 3.2 (see Fig. 5).

The SLM-coupled seriously underestimates the sensible heat flux from March through July (Fig. 11). As described in Section 1, three surface layers and simpler vegetation information with prescribed surface parameters (e.g. soil moisture, albedo and roughness) in the SLM may not be precise enough for successful simulation of these surface fluxes to assist the northward progression of the early monsoon system. Note that the observed sensible heat flux undergoes a dramatic drop during May through July (solid line, Fig. 11). The CLM2-coupled partly reproduces this seasonal change. However, the SLM-coupled produces the steady sensible heat flux value with time.

\subsection{Spatio-temporal variation of precipitation}

The surface heating distributions and latent/sensible heat fluxes generated by the 2 different land models produce obviously different seasonal evolution of the monsoon precipitation. The climatological seasonal monsoon evolution in terms of precipitation is plotted from May through August including the monsoon development stage in May and June (Fig. 2), and the mature monsoon stage in July and August (Fig. 3). Compared with the SLM-coupled, the CLM2-coupled better simulates the observational patterns in May and June in terms of location of the maximum precipitation zone. For instance, the maximum precipitation west and east of India in June is successfully simulated by the CLM2-coupled (Fig. 2e,f). The difference map 


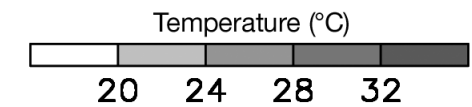

a) ERA40 (Tsfc)
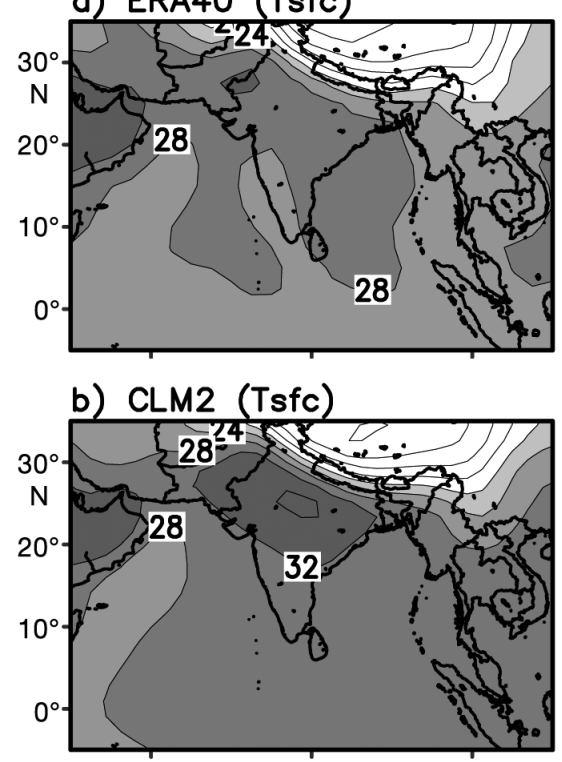

c) SLM (Tsfc)

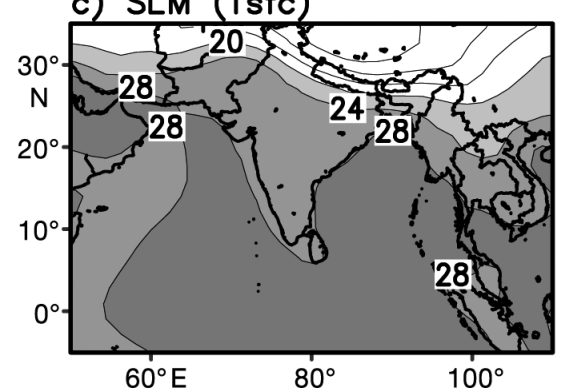

d) Tsfe over India

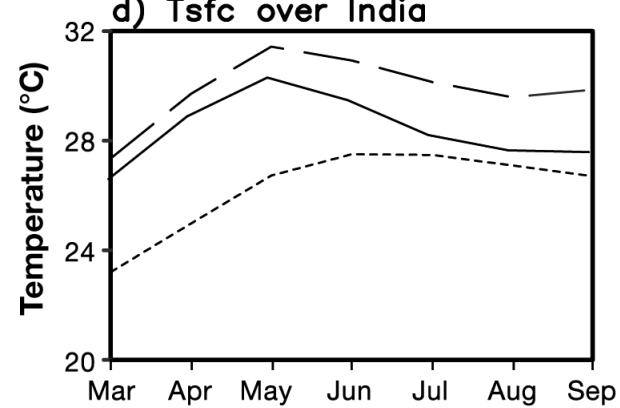

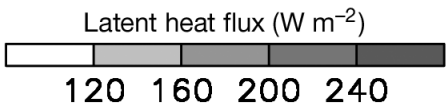

e) ERA40 ( $\mathrm{LH})$

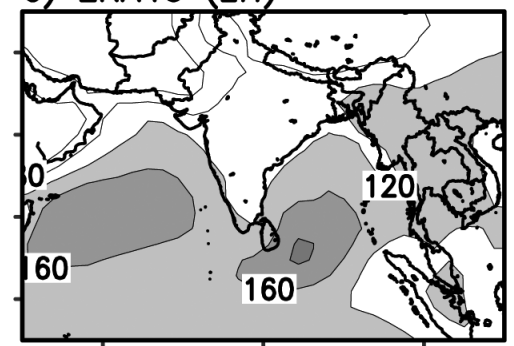

f) $\mathrm{CLM} 2(\mathrm{LH})$

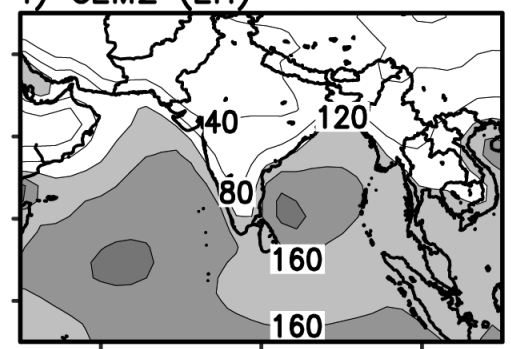

g) SLM (LH)

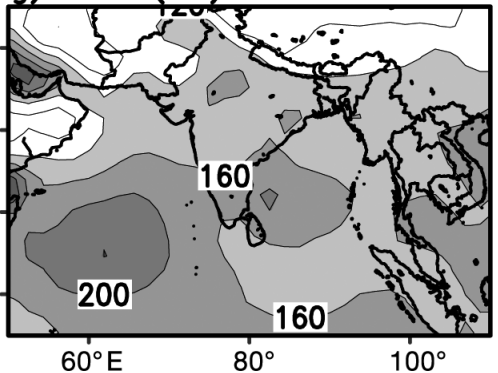

h) LH over India

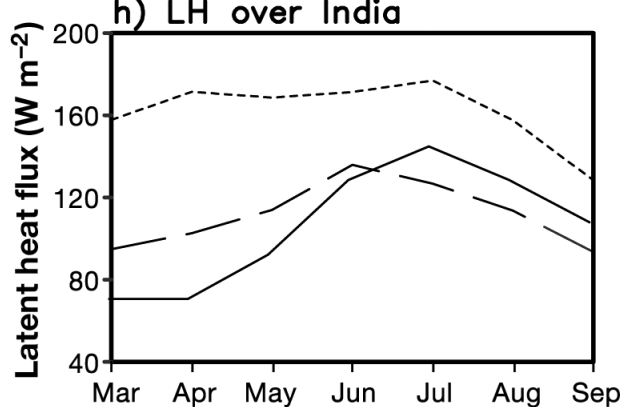

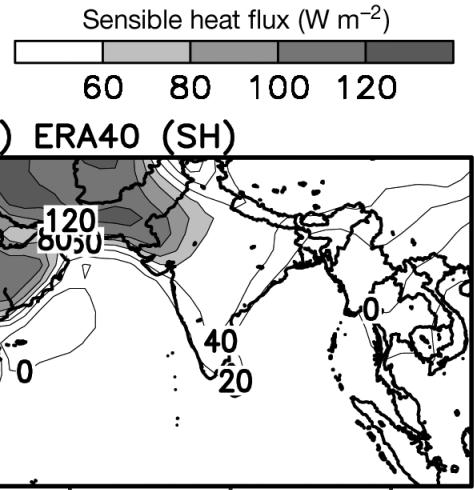

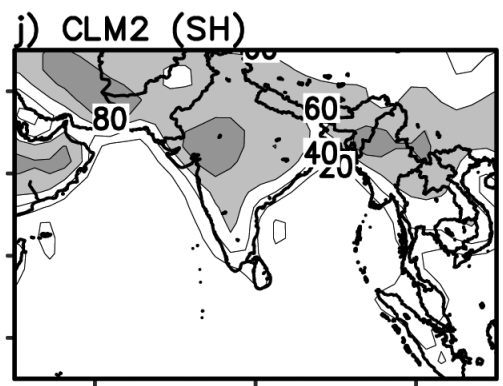

k) $\mathrm{SLM}(\mathrm{SH})$
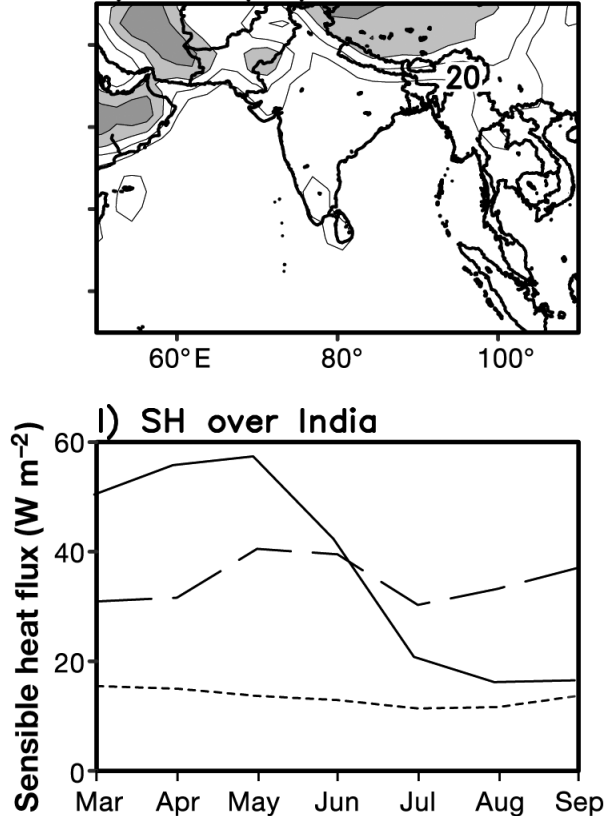

Fig. 1. Climatological mean distribution of surface temperature (Tsfc, left), latent heat flux (LH) (middle) and sensible heat flux (SH) (right) averaged from May through September. Top row: field obtained from the ERA40 reanalysis, 2nd row: simulation with the comprehensive land model (CLM2) and 3rd row: simulation with the simple land model (SLM). Bottom row represents the climatological evolution of the 3 variables (surface temperature, latent heat and sensible heat) averaged over the Indian region $\left(72.5-85^{\circ} \mathrm{E}, 7.5-25^{\circ} \mathrm{N}\right)$ at monthly temporal steps. ERA40 reanalysis and the CLM2-coupled and SLM-coupled simulations are denoted by solid, long-dashed and short-dashed lines, respectively. Note that the sea surface temperatures (SST) for CLM2 and SLM are the prescribed Reynolds SST. EQ: equator

(Fig. 2h) clarifies that the CLM2-coupled distributes the precipitation west and east of India, whereas the precipitation simulated by SLM-coupled is distributed south of India (Fig. 2g,h).
Fig. 3 represents the precipitation patterns for July and August. Overall, spatial patterns indicate that the SLM-coupled performs comparably to CLM2-coupled. The precipitation zone simulated by the SLM-coupled 

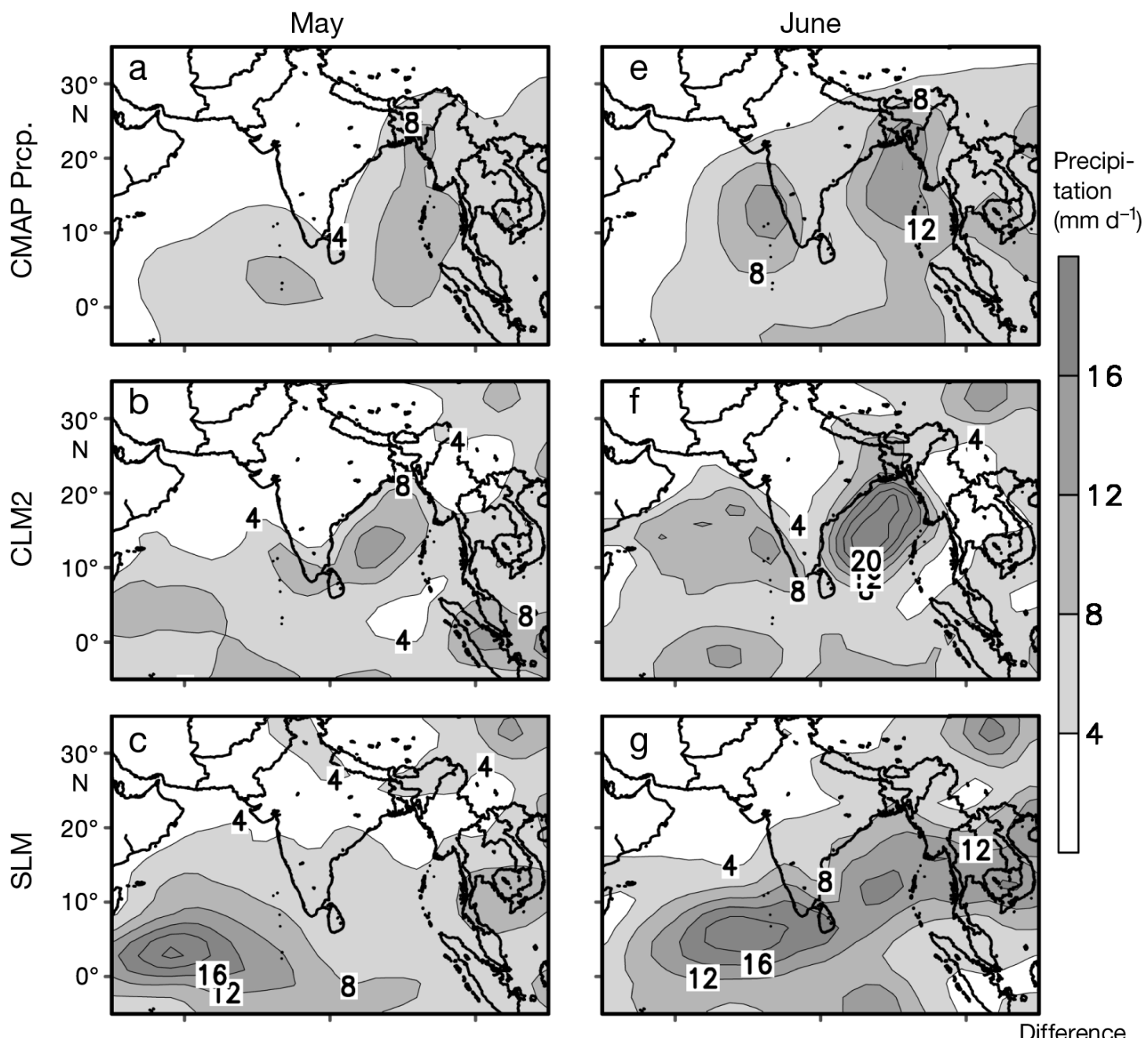

Fig. 2. Geographical distributions of climatological precipitation $\left(\mathrm{mm} \mathrm{d}^{-1}\right)$ in the monsoon development stage for May (left column) and June (right column). First 3 rows: spatial
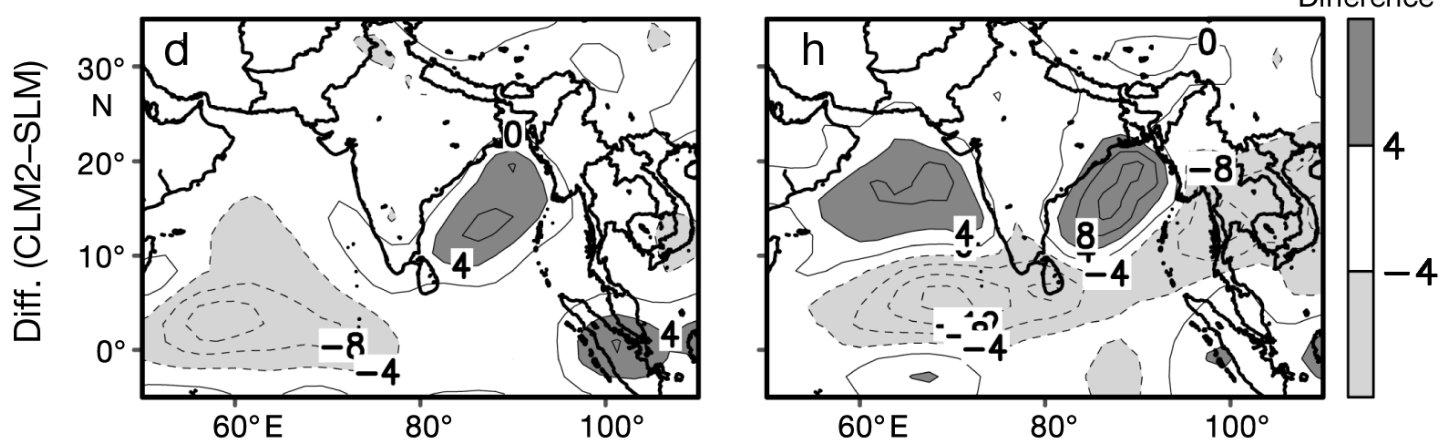
distribution obtained from Climate Prediction Center Merged Analysis of Precipitation (CMAP) and the CLM2-coupled and SLM-coupled simulations, respectively. Bottom row: difference between the 2 simulations (CLM2 minus SLM). EQ: equator

progresses northward as far as the precipitation zone produced by the CLM2-coupled. An outstanding difference is the greater amount of rainfall produced by the SLM-coupled compared with that produced by the CLM2-coupled and the observations. This excessive precipitation by SLM-coupled is clearly shown in the Indian seasonal precipitation time series in Figs. 4 \& 5 . This overestimated rainfall from a simple land surface representation was also found in Xue et al. (2004), in which the simple land surface parameterization with- out explicit vegetation representation produced excessive monsoon precipitation. Synoptic features from surface to upper levels show the possible reasons for overestimated rainfall. As discussed earlier, the area over India is characterized by excessive latent heat release sustained over the entire monsoon period (Fig. 1h). In addition, the surface heating over land increases from July onwards (Fig. 1d), and the sea level pressure low over land reaches a peak in July accordingly (see Fig. 10a). The strong lower-level con- 

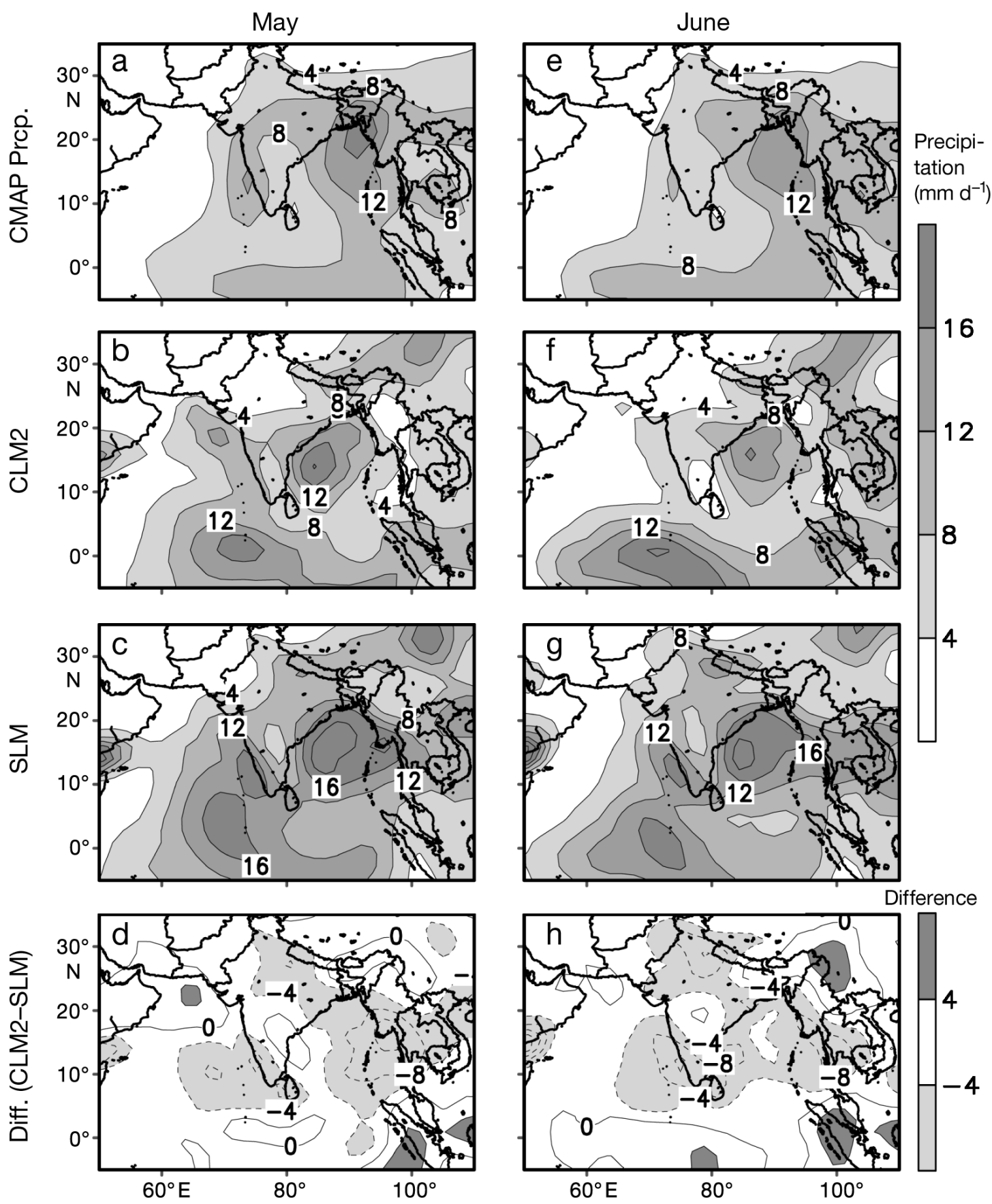

Fig. 3. Same as Fig. 2, but for the mature monsoon stage: July (left column) and August

(right column)

vergence and upper-level divergence structure is built up in July and August (see short dashed line, Fig. 10b,c) and is dynamically consistent with the surface heating and pressure patterns. These structures are favorable for ascending motion with a lower-level flow from the ocean and appear to be plausible causes of the overestimated rainfall in the SLM-coupled.

Spatial correlations of the climatological precipitation patterns are calculated at $15 \mathrm{~d}$ temporal steps through the complete monsoon period (May to Sep- tember) to assess the model capability for producing the monsoon evolution more precisely. The resulting spatial correlations are listed in Table 1. Correlation coefficients between CMAP observations and the CLM2-coupled range from 0.54 to 0.65 , whereas those between CMAP observations and the SLM-coupled range from 0.41 to 0.66 . The CLM2-coupled shows higher correlation coefficients in the monsoon development stage (e.g. May and June) and the later stage (the second half of August and September). The SLM- 


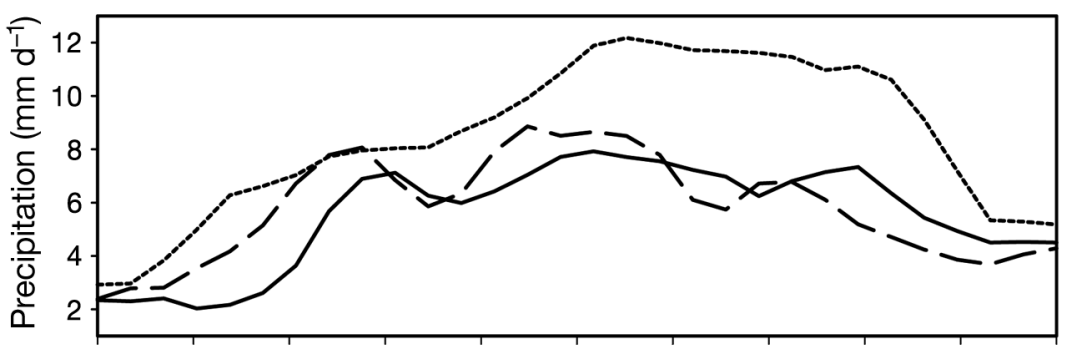

May 1 May 16 May31 Jun 15 Jun 30 Jul 15 Jul 30 Aug 14 Aug $29 \operatorname{Sep} 13 \operatorname{Sep} 28$

Fig. 4. Temporal evolution of the climatological pentad precipitation averaged over India and the surrounding oceanic area $\left(72.5-85^{\circ} \mathrm{E}, 7.5-25^{\circ} \mathrm{N}\right)$, May-September. Solid, long-dashed and short-dashed lines: precipitation obtained from CMAP observations and the CLM2-coupled and SLM-coupled simulations, respectively

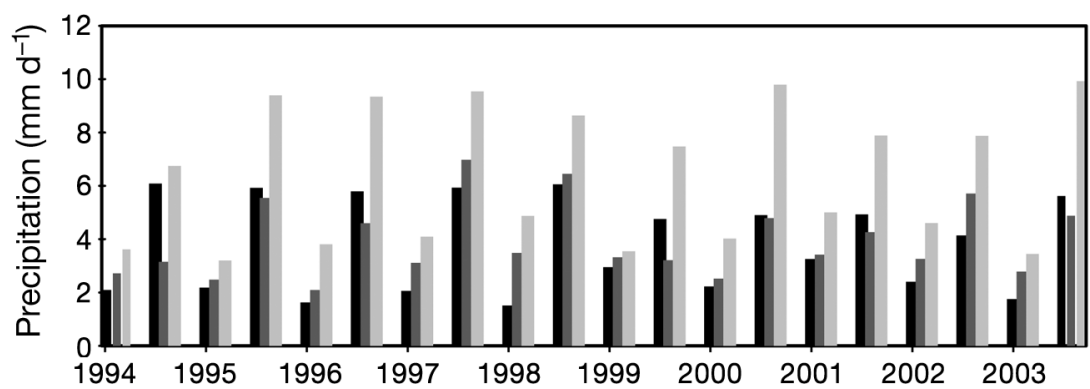

Fig. 5. Annual variation of the Indian seasonal precipitation $\left(72.5-85^{\circ} \mathrm{E}, 7.5-25^{\circ} \mathrm{N}\right)$ over 10 years (1994-2003). Pentad precipitation is averaged over the pre-monsoon and monsoon development (AMJ) and mature monsoon stages (JAS) to obtain the seasonal precipitation each year. Black, dark grey and light grey bars: precipitation obtained from CMAP observations and the CLM2-coupled and SLM-coupled simulations, respectively

coupled shows higher correlation coefficients in July and the first half of August, although the difference in correlation values between the 2 models is not remarkably large. The change in correlation coefficients with time (Table 1) demonstrates that the CLM2-coupled plays a positive role in improving the precipitation distribution in the pre-monsoon (May) and monsoon development stages (June), but not in the mature

Table 1. Spatial correlations of the climatological precipitation patterns at $15 \mathrm{~d}$ temporal steps for the complete monsoon period (May to September) between CMAP observations and the CLM2-coupled and SLM-coupled simulations

\begin{tabular}{|lcc|}
\hline & CLM2-coupled & SLM-coupled \\
\hline 1-15 May & 0.62 & 0.41 \\
16-30 May & 0.54 & 0.49 \\
31 May-14 Jun & 0.56 & 0.53 \\
15-29 Jun & 0.56 & 0.52 \\
30 Jun-14 Jul & 0.54 & 0.57 \\
15-29 Jul & 0.54 & 0.66 \\
30 Jul-13 Aug & 0.60 & 0.63 \\
14-28 Aug & 0.64 & 0.59 \\
29 Aug-12 Sep & 0.56 & 0.52 \\
13-27 Sep & 0.65 & 0.56 \\
\hline
\end{tabular}

monsoon stage (July and August). This difference in performance of the CLM2-coupled between the 2 monsoon stages is also evident from the interannual variation in precipitation (Fig. 5).

The excessively high land surface temperatures (Fig. 1d), with little reduction in sensible heat flux (Fig. 11), in the mature stage appear to produce an underestimated latent heat flux (Fig. 1h) over India. Although the increased land surface temperature plays a positive role in reducing the surface temperature bias and enhancing the differential heating distribution in the monsoon development stage, the excessively high bias of this temperature in the mature stage may yield poor performance of the CLM2-coupled by producing an underestimated latent heat flux and an overestimated sensible heat flux (Fig. 1h,l). The soil moisture fluxes (soil moisture and evaporation from ground and canopy), which are important for atmospheric moisture convergence (Yasunari et al. 2006), may be inter-related to this underestimated latent heat flux. They do not correlate well with the atmospheric lower-level wind convergence relative to monsoon development phase (Table 2).

Fig. 4 shows the seasonal variation in the climatological pentad precipitation averaged over the Indian land mass and the surrounding oceanic area $\left(72.5-85^{\circ} \mathrm{E}\right.$, $7.5-25^{\circ} \mathrm{N}$ ). The precipitation simulated by CLM2coupled exhibits variation closer to that of the CMAP observations. The simulated precipitation by the SLMcoupled apparently overestimates the observed precipitation. Overestimation is far more serious in July, August and the first half of September. The first observed peak in early June associated with the Indian monsoon onset is successfully realized by the CLM2coupled. However, the CLM2-coupled tends to capture it earlier than the CMAP observations. The SLMcoupled seems to show a gradual precipitation increase during that period.

The second observed peak is reproduced in July by the CLM2-coupled. The precipitation amount at this stage is larger than that in the first peak in June. The CLM2-coupled and CMAP observations both show this second peak reasonably well. By contrast, the SLM-coupled produces a continuous increase in precipitation and overestimation until early September. 
Interannual variation in the Indian seasonal precipitation was also assessed by temporal correlation. The area-averaged precipitation over India was seasonally averaged to obtain the seasonal precipitation (3 mo mean) for the pre-monsoon and monsoon development period (AMJ) and the mature monsoon period (JAS). The resulting precipitation is plotted in Fig. 5. It is evident that the SLM-coupled run overestimates the precipitation compared to the CMAP observations. The bias values for the AMJ and JAS periods are 1.81 and $3.25 \mathrm{~mm} \mathrm{~d}^{-1}$, respectively, whereas the bias value for the CLM2-coupled are 0.72 and $-0.45 \mathrm{~mm} \mathrm{~d}^{-1}$, respectively. The RMS values for the random error term for AMJ and JAS are 0.51 and $1.23 \mathrm{~mm} \mathrm{~d}^{-1}$, respectively, by CLM2-coupled, whereas the SLM-coupled shows 0.70 and $1.08 \mathrm{~mm} \mathrm{~d}^{-1}$, respectively. This indicates that the CLM2-coupled outperforms the SLM-coupled in the monsoon development stage in terms of RMS error. The increase in the temporal correlation by the CLM2coupled is also pronounced in the monsoon development stage. Correlation coefficients are 0.45 (AMJ) and 0.25 (JAS) for the CLM2-coupled, whereas the SLMcoupled yields values of 0.21 (AMJ) and 0.27 (JAS), respectively. Note that the climatological seasonal mean values are subtracted from the precipitation data before calculating RMS and correlation coefficients. The RMS and correlation coefficients indicate that even the simple land surface treatment was able to produce precipitation comparable to the advanced land surface treatment in the mature monsoon period. As shown in Table 2, correlations between soil moisture, near surface evaporation and lower-level (1000 mb) atmospheric wind convergence in the CLM2-coupled identify a closer relationship in the monsoon development stage than in the mature monsoon stage.

\subsection{Lower- and upper-level circulation structures}

For further investigation of the monsoon responses to the different land surface models, lower- $(850 \mathrm{mb})$ and upper-level (200 mb) circulation and the resulting con-

Table 2. Temporal correlations of lower-level convergence (1000 mb) with soil moisture variability and near surface evaporation (ground plus canopy) produced in the CLM2coupled simulation

\begin{tabular}{|lcc|}
\hline Month & $\begin{array}{c}\text { Convergence vs. } \\
\text { soil moisture } \\
\text { r }\end{array}$ & $\begin{array}{c}\text { Convergence } \\
\text { vs. evaporation } \\
\text { r }\end{array}$ \\
\hline May & 0.75 & 0.85 \\
Jun. & 0.88 & 0.91 \\
Jul. & 0.65 & 0.62 \\
Aug. & -0.60 & -0.38 \\
Sep. & -0.66 & -0.45 \\
\hline
\end{tabular}

vergence/divergence are presented in Figs. 6-9 for the monsoon development (May and June) and the mature monsoon stages (July and August). Seasonal evolution of the sea level pressure, lower-level convergence and upper-level divergence over the Indian region for the complete monsoon period is presented in Fig. 10. Simulation using the CLM2-coupled and SLM-coupled produces the circulation features for monsoon development at the 850-mb level, including the southwesterly jet with its core headed towards continental India (Fig. 6). As documented in Halpern \& Woiceshyn (1999), this lower-level flow is crucial for moisture and energy transport to the Indian monsoon region and contributes to rainfall over western India and the Bay of Bengal (see Fig. 2). This southwesterly jet, the northern branch of a cross-equatorial flow coming from the Arabian Sea, is seen also in the SLM-coupled (Fig. 6c,g). However, the opposite thermal contrast appears to hinder the enhancement of this flow northward, as the core of this jet and the corresponding convergence zone are displaced southward compared with the CMAP observations and the CLM2-coupled (Fig. 6d,h).

On the difference map in Fig. 6, the dark-shaded region indicates more convergence by the CLM2-coupled than by the SLM-coupled over the Indian Ocean along $10^{\circ} \mathrm{N}$ (May) and $12-13^{\circ} \mathrm{N}$ (June) west and east of India. The light-shaded region is found south of the dark-shaded region, indicating more convergence by the SLM-coupled south of $10^{\circ} \mathrm{N}$. More lower-level convergence by the CLM2-coupled is also found over India, spreading across the central and northern parts. For the SLM-coupled, the lower-level convergence over India is not as clearly seen relative to the CLM2coupled. The difference in flow vectors passing through India is westerly in June (Fig. 6h), indicating stronger westerly flow predicted by the CLM2-coupled. In May, this difference in flow vectors over India forms the cyclonic circulation that is linked to stronger lowerlevel convergence by the CLM2-coupled (Fig. 6d). Consequently, compared with the SLM-coupled, the lower-level circulation in the monsoon development stage by the CLM2-coupled can be summarized as a stronger westerly jet over the Indian monsoon area and a more realistic latitudinal location of the jet core and corresponding convergence. Patterns produced by the SLM-coupled (Fig. 6c,g), by contrast, are not consistent with the observations in terms of the latitudinal location. The lower-level jet core and convergence are restricted to the south of $10^{\circ} \mathrm{N}$.

Improvement of the lower-level circulation characteristics by the CLM2-coupled over the SLM-coupled is not clearly seen in July and August (mature monsoon stage) (Fig. 7). The lower-level southwesterly jet in the SLM-coupled (Fig. $7 \mathrm{C}, \mathrm{g}$ ) is stronger than that in 

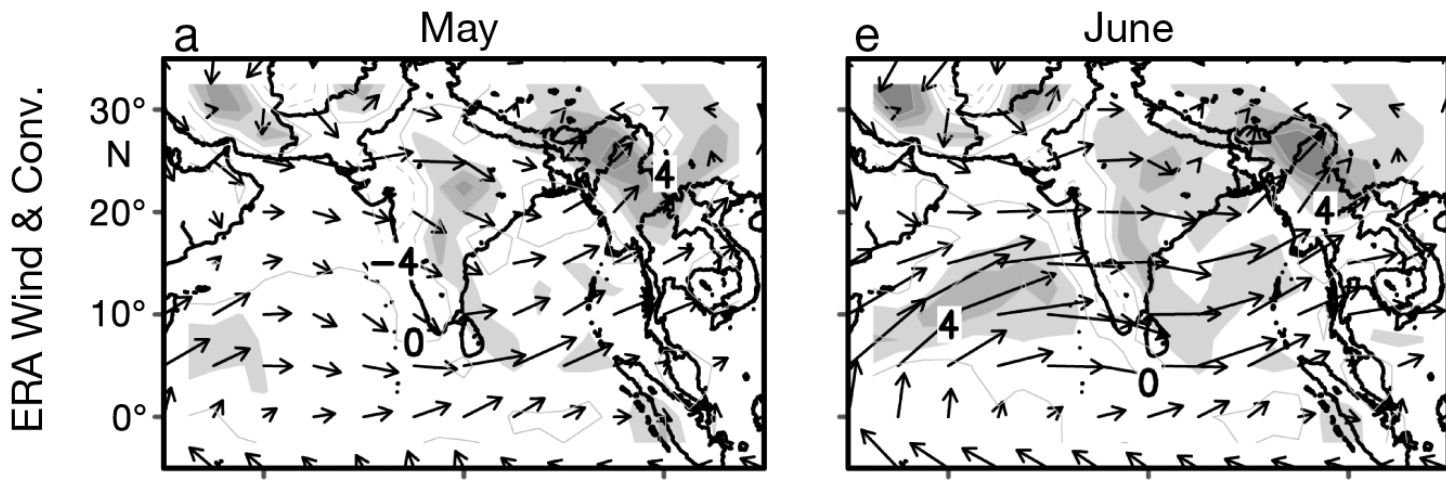

Con-

vergence

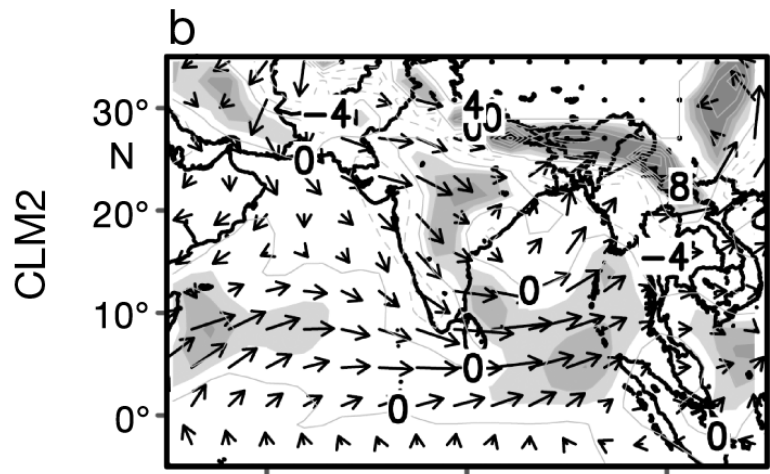

f

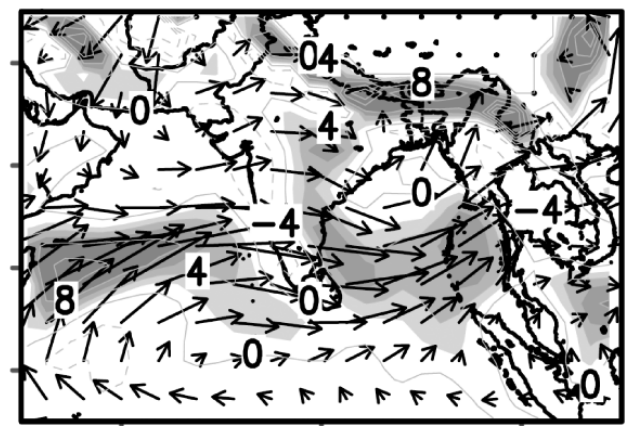

8

$\left(10^{-6} \mathrm{~s}^{-1}\right)$
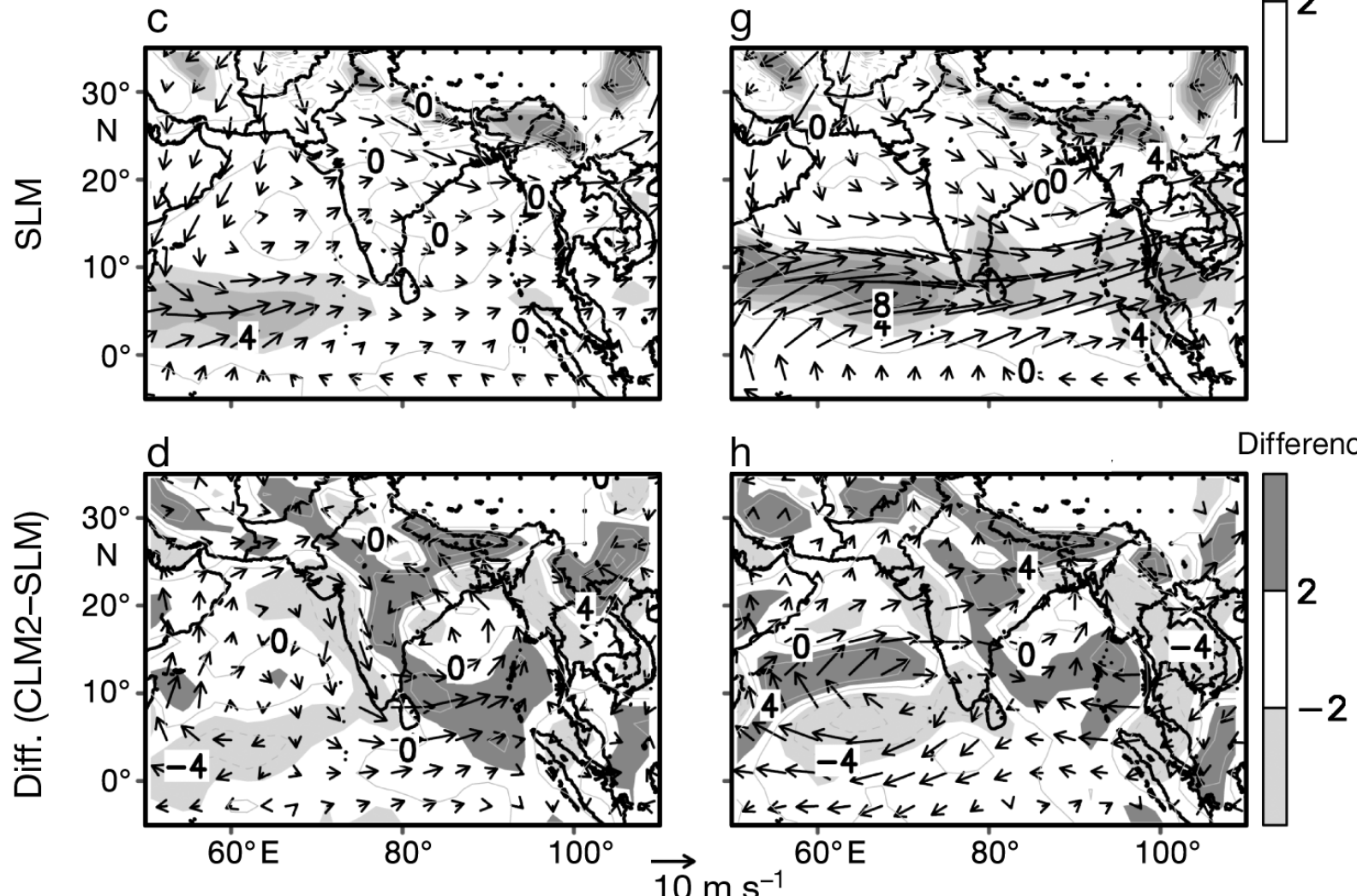

Fig. 6. Geographical distributions of climatological lower-level (850 mb) monsoon circulation (wind) and convergence in the monsoon development stage for May (left column) and June (right column). First 3 rows: spatial distribution obtained from CMAP observations and the CLM2-coupled and SLM-coupled simulations, respectively. Convergent (divergent) areas are contoured solid (dashed) and shaded dark (light). Bottom row: difference between the 2 simulations (CLM2 minus SLM). The scale of the wind speed is shown below the bottom panel with an arrow 

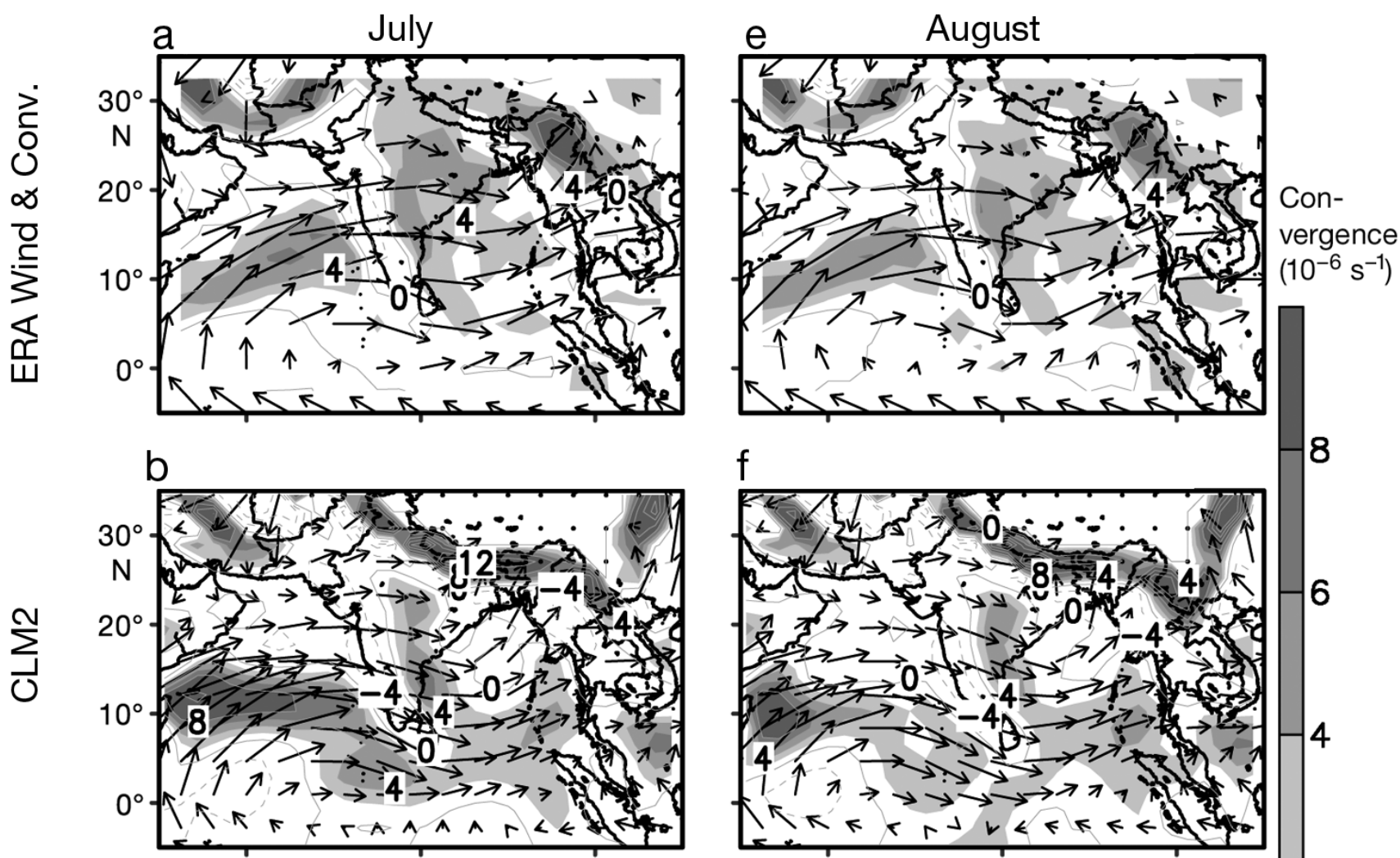

$f$

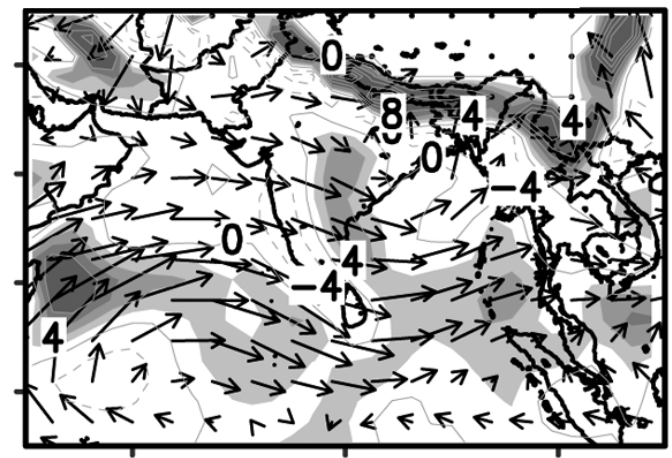

8

9
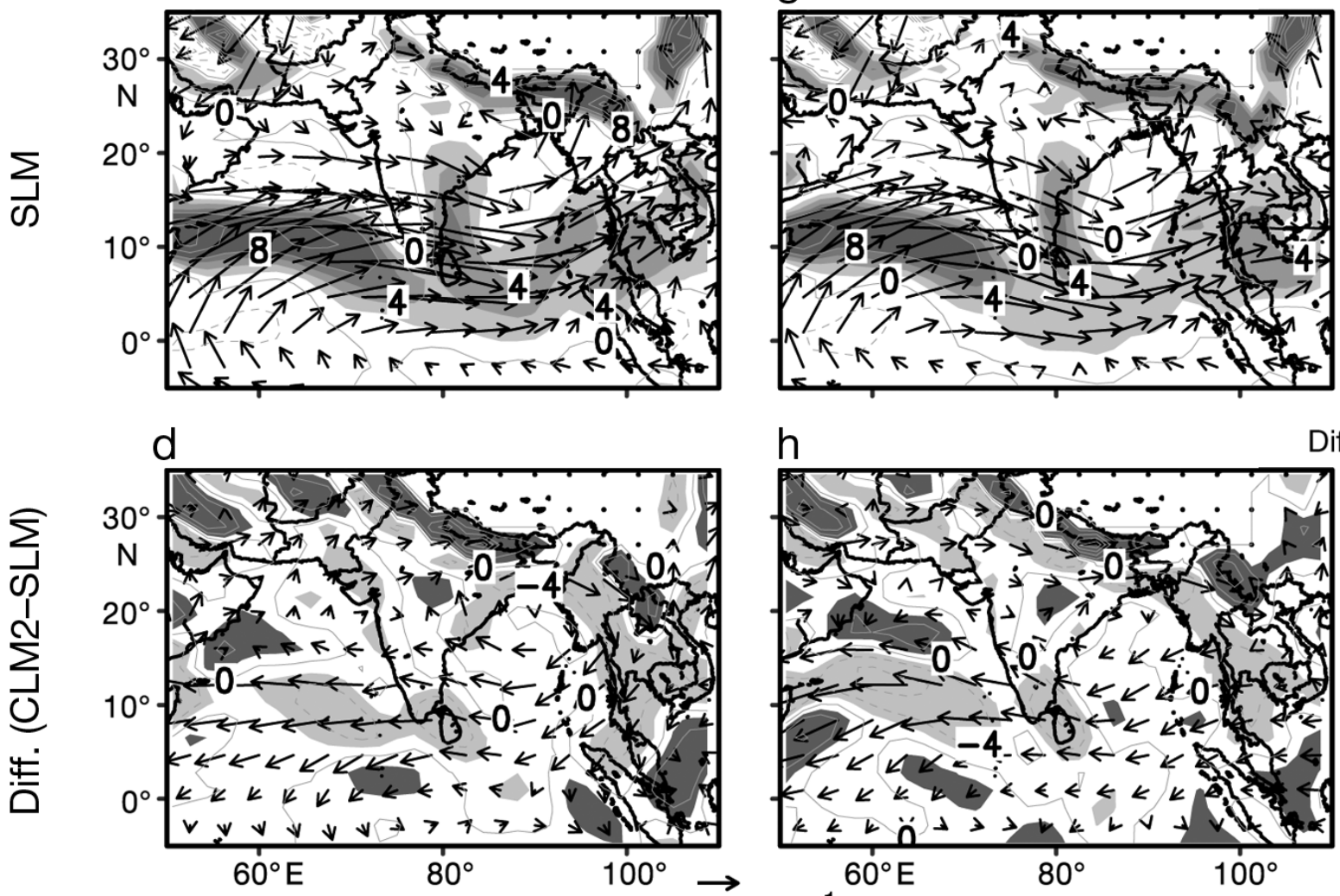

$\mathrm{h}$

Difference

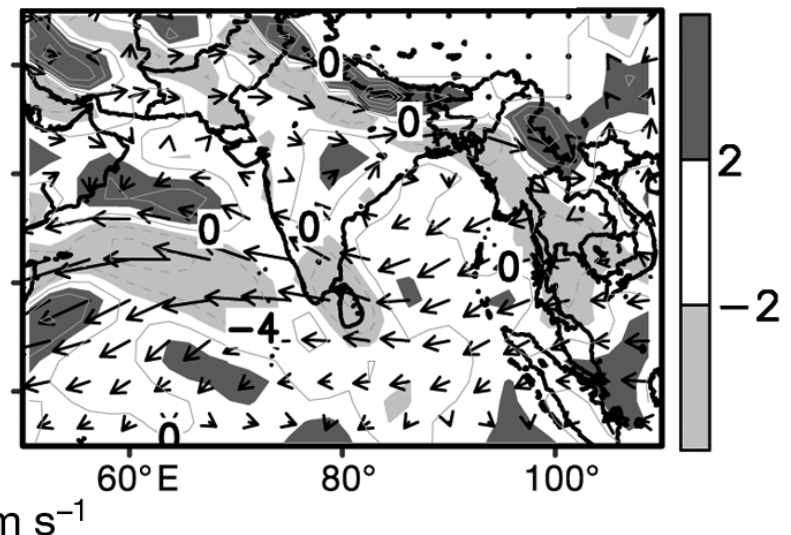

Fig. 7. Same as Fig. 6 but for July (left column) and August (right column) 

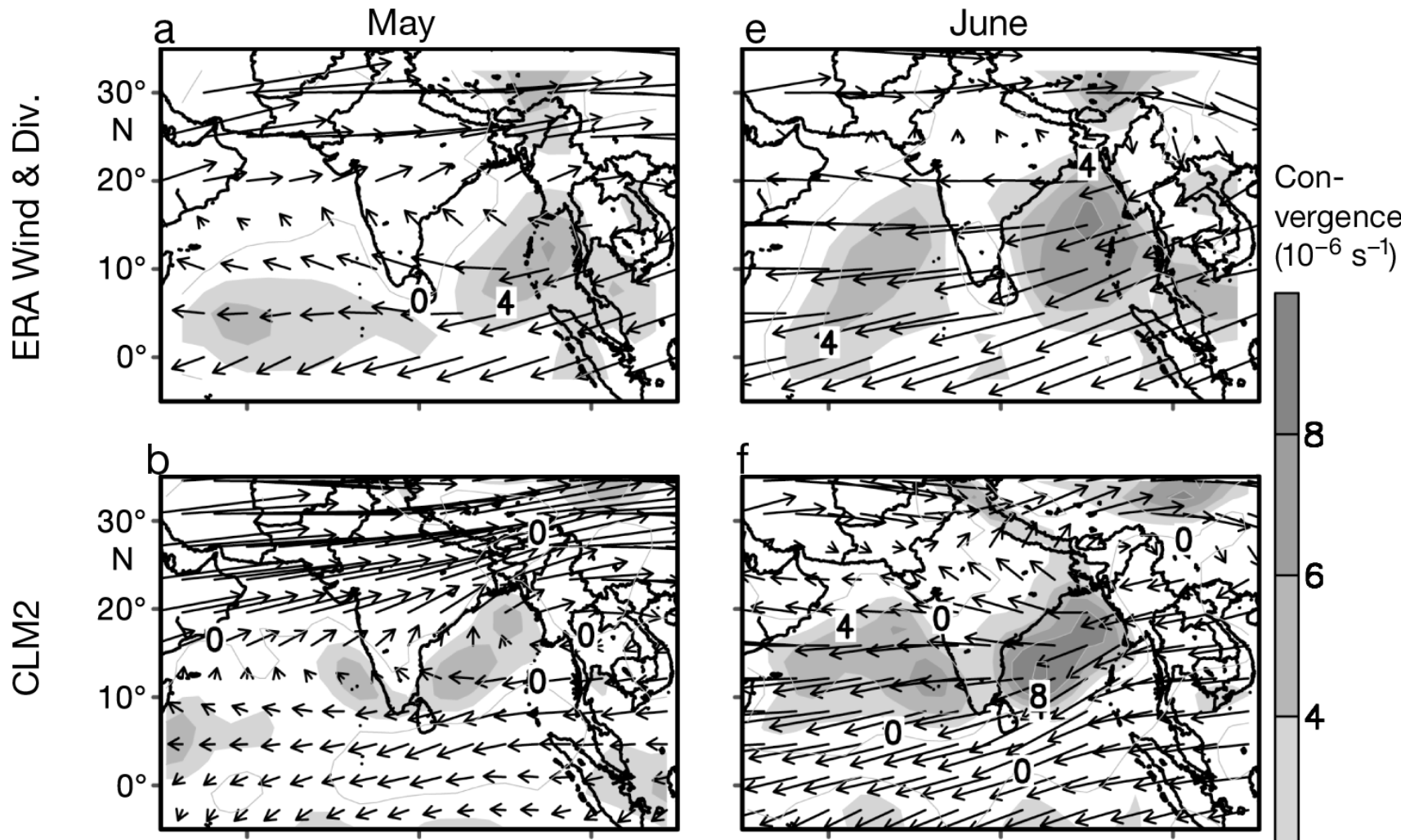

8
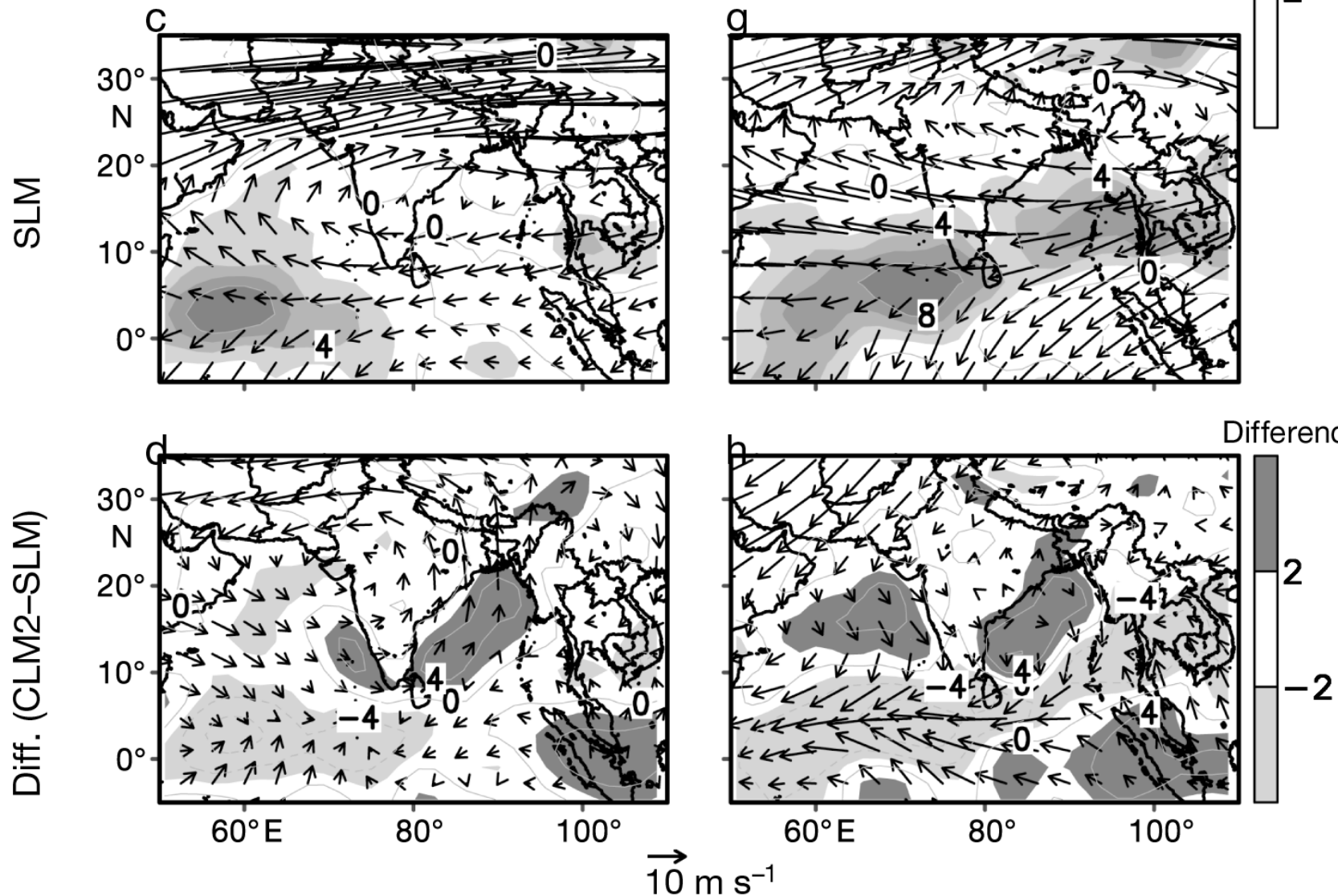

Fig. 8. Same as Fig. 6 but for upper-level (200 mb) circulation and divergence. Left column: May; right column: June 

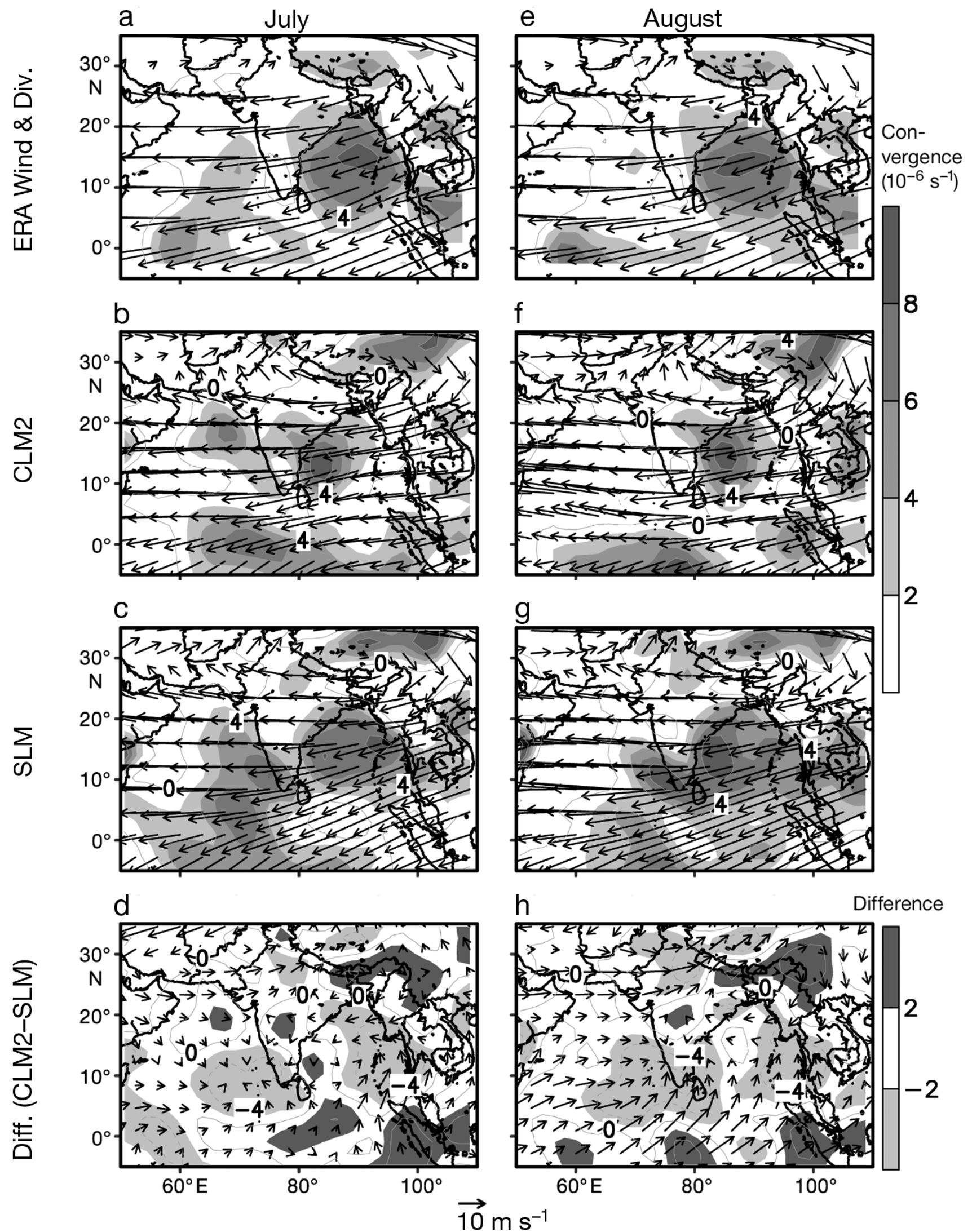

Fig. 9. Same as Fig. 8 but for July (left column) and August (right column) 

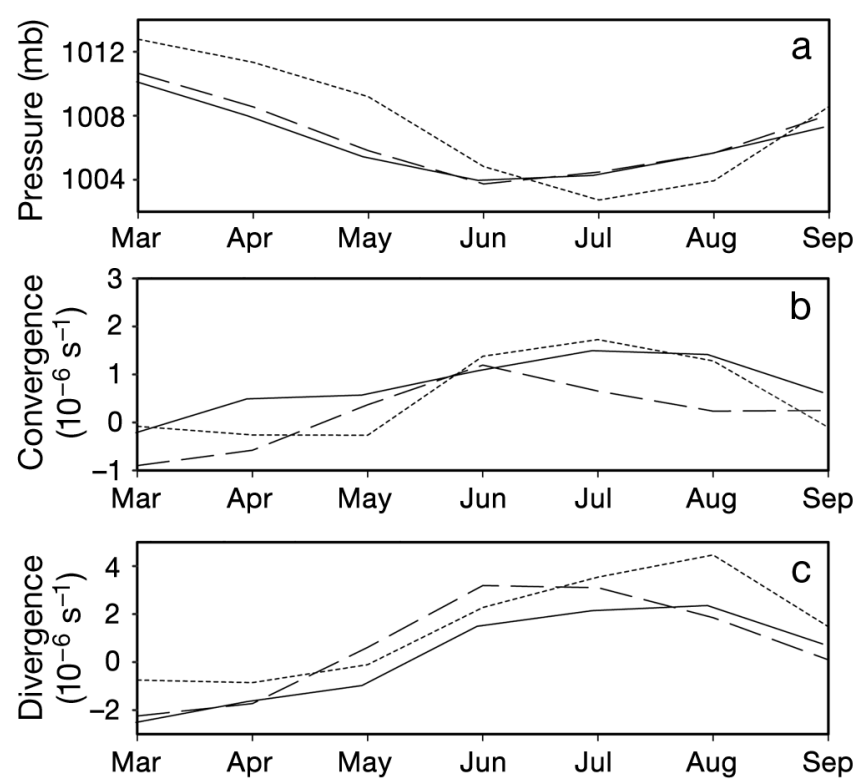

Fig. 10. Temporal evolution of the climatological monthly (a) sea level pressure, (b) $850 \mathrm{mb}$ convergence and (c) $200 \mathrm{mb}$ divergence averaged over India $\left(72.5-85^{\circ} \mathrm{E}, 7.5-25^{\circ} \mathrm{N}\right)$. ERA40 reanalysis and the CLM2-coupled and SLM-coupled simulation data are denoted by solid, long-dashed and short-dashed lines, respectively

the CLM2-coupled (Fig. 7b,f), as the difference map clearly shows the easterly component over the southern part of India (Fig. 7d,h). This indicates more moist air transported from the western Indian Ocean in the SLM-coupled. The latitudinal location of the jet core is around $15^{\circ} \mathrm{N}$ in both simulations. Although the CLM2coupled shows more convergence over central India (Fig. $7 \mathrm{~d}, \mathrm{~h}$ ), it is smaller in magnitude than that seen in May and June (Fig. 6d,h).

The upper-level circulation and divergence in the monsoon development stage shows a typical strong westerly in the mid-latitude region and an easterly over the low-latitudinal region (Fig. 8) (Lim et al. 2002). The large-scale anticyclonic outflow from the Tibetan Plateau, which is a consequence of continental diabatic heating (Meehl 1994, Li \& Yanai 1996), is reproduced similarly in the 2 models and the ERA40 reanalysis. However, the divergence field that is vertically connected with lower-level convergence west and east of India is better established by the CLM2coupled (Fig. 8b-d,f-h). The divergence is centered over western India and the Bay of Bengal as a consequence of the convective column with a strong ascending motion. By contrast, the SLM-coupled produces weaker divergence over the region and excessive divergence over the equatorial Indian Ocean, as shown in the difference map (Fig. 8d,h).

The upper-level circulation in July and August does not exhibit a marked difference between the 2 simula- tions. The gigantic anticyclonic circulation and strong easterly wind passing through the South Asian region is well organized by both the CLM2-coupled (Fig. 9b,f) and the SLM-coupled (Fig. 9c,g). Specifically, stronger divergence than the CLM2-coupled (Fig. 9b,f) and the ERA reanalysis (Fig. 9a,e) is produced by the SLMcoupled over the southern part of India (Fig. 9c, d, g,h), implying stronger vertical ascending motion with potential rainfall processes. Linkage with lower-level circulation, as illustrated in Fig. 7 indicates that, in July and August, the SLM-coupled produces stronger lower-level convergence and upper-level divergence than the CLM2-coupled, resulting in stronger upward motion by the SLM-coupled over southern India. By contrast, the central part of India is expected to have more upward motion in the CLM2-coupled simulations than in the SLM-coupled simulations (Figs. 7d,f \& 9d,f).

Seasonal evolution of the area-averaged sea level pressure, lower-level $(850 \mathrm{mb})$ convergence and upperlevel $(200 \mathrm{mb})$ divergence over India is plotted with respect to the CLM2-coupled and SLM-coupled simulations (Fig. 10). Time series is plotted with monthly interval from March through September. It is clear from the comparison that the CLM2-coupled reaches the highest or lowest peaks in June. The lowest sea level pressure representing the monsoon trough (Zhang \& Krishnamurti 1996) is found in June by the CLM2coupled in accordance with the CMAP observations (Fig. 10a). However, the simulated largest lower- and upper-level convergence/divergence does not appear in July, as seen in the observations (Fig. 10b,c). In particular, the lower-level convergence is largely reduced in the mature phase. The underestimated precipitation in the mature monsoon stage (Fig. 5) seems attributable to this relatively weaker convergence/divergence (Fig. 10b,c). This weaker convergence/divergence is in turn associated with underestimated latent heat flux (Fig. 1h), which may affect the relationship between surface moisture fluxes and lower-level atmospheric circulation (Table 2). As described in the previous section, the underestimated latent heat flux is a result of excessive land surface temperature and overestimated sensible heat flux in the mature monsoon stage.

The SLM-coupled shows the peaks in July and August. Although the sea level pressure shows a lagged minimum as compared with observations and CLM2-coupled (Fig. 10a), the simulated convergence/ divergence is more realistic than that of the CLM2coupled (Fig. 10b,c). This condition favors precipitation over this region. However, lower sea level pressure (Fig. 10a), stronger upper-level divergence and the excessive latent heat release (Fig. 1h) in comparison to observations contribute to the considerable overestimation of precipitation in the mature monsoon stage, as we discussed in reference to Figs. $4 \& 5$. 


\section{DISCUSSION AND CONCLUDING REMARKS}

The present study investigated the seasonal evolution of the Indian summer monsoon with and without the comprehensive land surface model, which may play an important role in determining the differential heating distribution and surface thermodynamic fluxes. In order to evaluate whether the comprehensive land surface treatment necessarily outperforms the simple land surface treatment and how the influence of these land surface treatments differs with respect to monsoon phases (i.e. development and mature phases), we coupled the FSU/COAPS atmospheric climate model with the CLM2-coupled as well as with the SLM-coupled. The simulated evolutions under these 2 different atmosphere-land couplings were compared for the entire summer monsoon period, and plausible causes for different monsoonal fields simulated by the 2 different land surface treatments were investigated.

In the monsoon development stage (May and June), spatial patterns of land surface temperature and circulation are noticeably improved by the CLM2-coupled. Simulated Indian monsoon developments at surface, lower and upper levels indicate that the relative impact of the CLM2-coupled versus the SLM-coupled is the reduction in surface cold biases over India, providing a reliable distribution of differential heating. More detailed vertical structures of the soil temperature and moisture, vegetation information and frequent interactions of the surface and atmospheric variables under the atmosphere-land coupling strategy may lead to the realistic surface sensible and latent heat flux distributions. These improved distributions may play a positive role in producing a more realistic surface heating distribution that facilitates the early monsoon development. The resulting location and timing of the monsoon trough over India at surface level are reasonably reproduced. Lower- $(850 \mathrm{mb})$ and upper-level $(200 \mathrm{mb})$ monsoon circulations and convergence/divergence patterns are also simulated quite closely to observations by the CLM2-coupled. However, a series of discrepancies between observations and modeled fields is found when only the simple land surface process is considered. It appears that unrealistic differential heating distributions in May and June due to the continental cold biases provide a poor condition for northward progression of the monsoon system, resulting in a monsoon circulation and precipitation zone over the Indian Ocean displaced southward compared with observations in the monsoon development stage.

Improvement by the CLM2-coupled is, however, not as evident in July and August (mature monsoon stage). The CLM2-coupled fails to reproduce the observed significant drop in sensible heat flux in July. The influ- ence of the increase in land surface temperature of the CLM2-coupled simulation in the monsoon development phase seems to remain strong in the mature phase, resulting in little reduction in sensible heat flux and smaller increases in the latent heat flux than observations (Fig. 1d,h,l). As a result, the simulated latent heat flux, which is larger than observations in the monsoon development phase for the Indian region, is smaller than observations in the mature monsoon phase. This effect suppresses precipitation processes and yields a negative precipitation bias for the 10 monsoon years $\left(-0.45 \mathrm{~mm} \mathrm{~d}^{-1}\right.$ for JAS), whereas the bias in the development phase is positive $\left(0.72 \mathrm{~mm} \mathrm{~d}^{-1}\right.$ for AMJ). Unsuccessful representation of latent heat flux seems related to the lower temporal correlations between surface moisture fluxes (soil moisture and evaporation) and lower-level convergence compared with those for the development phase. The resulting precipitation shows lower correlation with observations than that for the development phase. Although the value is not overwhelmingly high, the CLM2coupled exhibits a correlation coefficient of 0.45 in the monsoon development phase. This, however, decreases to 0.25 in the mature phase. RMS values for the random error term are also better in the monsoon development phase $\left(0.51 \mathrm{~mm} \mathrm{~d}^{-1}\right)$ than in the mature phase $\left(1.23 \mathrm{~mm} \mathrm{~d}^{-1}\right)$. Because of the large decrease in correlation and increase in RMS error in the mature phase, these values are never better than those in the SLM-coupled, which is described in the next paragraph. The only noticeable improvement by the CLM2-coupled in the mature stage is the dramatic reduction in wet bias seen in the SLM-coupled (3.25 to $-0.45 \mathrm{~mm} \mathrm{~d}^{-1}$ ).

Despite the poor conditions for monsoon development, the simulated precipitation amount over South Asia by the SLM-coupled is much larger than that of the observations and the CLM2-coupled. Overestimation of the precipitation by the SLM-coupled is more serious from July through early September. We speculate that this overestimated rainfall is due to the excessive latent heat release sustained over India. In addition, as the biases in the sensible/latent heat flux and surface heating distribution are reduced partly from July onwards in the SLM-coupled, the northward progression of the monsoon system seems less interrupted compared with the monsoon development stage. This could also give rise to overestimated rainfall over South Asia in July and August. The Indian seasonal precipitation biases are 1.81 and $3.25 \mathrm{~mm} \mathrm{~d}^{-1}$ for AMJ and JAS, respectively, which are larger in magnitude than those of the CLM2-coupled. Interannual variation in the Indian seasonal precipitation in terms of temporal correlation are 0.21 and 0.27 for AMJ and JAS, respectively. RMS values for the ran- 
dom error term are 0.70 and $1.08 \mathrm{~mm} \mathrm{~d}^{-1}$ for AMJ and JAS, respectively.

In conclusion, reliable atmosphere-land interactions are essential for producing realistic monsoon development. In the pre-monsoon/monsoon development phase, the seasonal aspects of Indian monsoon development were reproducible to a great extent by the comprehensive atmosphere-land coupling strategy in this study. However, the northward progression of the monsoon development system is not well simulated in the SLMcoupled because of a biased land surface temperature and latent/sensible heat fluxes. The superiority of the CLM2-coupled with the SLM-coupled in this study, however, seems limited to the monsoon development stage. The goal of our next study is to improve the simulation of the mature monsoon stage by achieving a realistic representation of the surface temperature, surface thermodynamic fluxes and their linkage to the lower-level circulation and convergence/divergence.

Acknowledgements. This work was funded by the Korea Meteorological Administration Research and Development Program under grant CATER (Center for Atmospheric Sciences and Earthquake Research) 2010-75.

\section{LITERATURE CITED}

Bonan GB, Olsen KW, Vertenstein M, Levis S and others (2002) The land surface climatology of the community land model coupled to the NCAR community climate model. J Clim 15:3123-3149

Cocke S, LaRow TE (2000) Seasonal predictions using a regional spectral model embedded within a coupled oceanatmosphere model. Mon Weather Rev 128:689-708

Dai Y, Zeng X, Dickinson RH, Baker I and others (2003) The common land model. Bull Atmos Meteorol Soc 84: 1013-1023

Halpern D, Woiceshyn PM (1999) Onset of the Somali Jet in the Arabian Sea during June 1997. J Geophys Res 104: 18041-18046

Kang HS, Hong SY (2008) An assessment of the land surface parameters on the simulated regional climate circulations: the 1997 and 1998 east Asian summer monsoon cases. J Geophys Res 113:D15121 doi:10.1029/2007JD009499

Editorial responsibility: Filippo Giorgi,

Trieste, Italy
Krishnamurti TN, Ramanathan Y (1982) Sensitivity of the monsoon onset to differential heating. J Atmos Sci 39: 1290-1306

Li C, Yanai M (1996) The onset and interannual variability of the Asian summer monsoon in relation to land-sea thermal contrast. J Clim 9:358-375

Lim YK, Kim KY, Lee HS (2002) Temporal and spatial evolution of the Asian summer monsoon in the seasonal cycle of synoptic fields. J Clim 15:3630-3644

Meehl GA (1994) Influence of the land surface in the Asian summer monsoon: external conditions versus internal feedbacks. J Clim 7:1033-1049

Reynolds RW, Rayner NA, Smith TM, Stokes DC, Wang W (2002) An improved in situ and satellite SST analysis for climate. J Clim 15:1609-1625

$>$ Rosmond TE (1992) The design and testing of the Navy operational global atmospheric system. Weather Forecast 7 : 262-272

Saha SK, Halder S, Kumar KK, Goswami BN (2010) Pre-onset land surface processes and 'internal' interannual variabilities of the Indian summer monsoon. Clim Dyn (in press) doi:10.1007/s00382-010-0886-z

> Shin DW, Cocke S, LaRow TE, O'Brien JJ (2005) Seasonal surface air temperature and precipitation in the FSU climate model coupled to the CLM2. J Clim 18:3217-3228

Sud YC, Smith WE (1985) Influence of local land-surface processes on the Indian Monsoon: a numerical study. J Appl Meteorol 24:1015-1036

> Xie P, Arkin PA (1996) Analyses of global monthly precipitation using gauge observations, satellite estimates, and numerical model predictions. J Clim 9:840-858

Xue Y, Huang HMH, Li WP, Prince S, DeFries R, Jiao Y, Vasic $\mathrm{R}$ (2004) Role of land surface processes in monsoon development: East Asia and West Africa. J Geophys Res 109: D03105 doi:10.1029/2003JD003556

> Xue Y, de Sales F, Li WP, Mechoso CR, Nobre CA, Juang HM (2006) Role of land surface processes in south American monsoon development. J Clim 19:741-762

- Yasunari T (2007) Role of land-atmosphere interaction on Asian monsoon climate. J Meteorol Soc Jpn 85B:55-75

> Yasunari T, Saito K, Takata K (2006) Relative roles of largescale orography and land surface processes in the global hydroclimate. I. Impacts on monsoon systems and the tropics. J Hydrometeorol 7:626-641

Zhang Z, Krishnamurti TN (1996) A generalization of Gill's heat-induced tropical circulation. J Atmos Sci 53:1045-1052

Zeng X, Shaikh M, Dai Y, Dickinson RE, Myneni R (2002) Coupling of the common land model to the NCAR community climate model. J Clim 15:1832-1854

Submitted: November 26, 2009; Accepted: October 12, 2010 Proofs received from author(s): January 20, 2011 